\title{
Penerapan Metode Analytical Hierarchy Process dalam Upaya Peningkatan Kualitas Objek Wisata
}

\author{
Application of Analytical Hierarchy Process \\ in Improving the Quality of Tourism Object
}

\author{
Robi Yanto \\ Sistem Informasi, STMIK Bina Nusantara Jaya Lubuklinggau \\ E-mail: wrtech2009@yahoo.co.id
}

\begin{abstract}
Abstrak
Objek wisata adalah perwujudan dari ciptaan manusia, tata hidup, seni budaya serta sejarah bangsa dan tempat keadaan alam yang mempunyai daya tarik untuk dikunjungi. Potensi objek wisata yang ada di Kota Lubuklinggau saat ini belum dikelola secara maksimal, sehingga keberadaan objek wisata belum mendapatkan respon positif dari wisatawan yang berkunjung. Hal ini dapat dilihat dari menurunnya jumlah wisatawan yang berkunjung setiap tahunnya. Salah satu faktor menurunnya jumlah wisatawan yang berkunjung adalah sumber daya objek wisata yang kurang memadai. Untuk dapat meningkatkan jumlah wisatawan yang berkunjung tentunya dibutuhkan sistem pendukung keputusan peningkatan kualitas objek wisata. Dimana kriteria yang digunakan berdasarkan hasil wawancara di Dinas Kebudayaan dan Pariwisata yaitu daya tarik, aksesibilitas, akomodasi dan sarana pendukung. Sistem pendukung keputusan ini menerapkan metode Analitical Hierarchy Process dengan software pengujian expert choice. Penelitian ini mempunyai tujuan agar dapat mengurangi penilaian secara subyektif terhadap peningkatan kualitas objek, sehingga menghasilkan sistem penilaian yang tepat dan objektif terhadap objek wisata yang akan dikembangkan.
\end{abstract}

Kata Kunci - Sistem Pendukung Keputusan, AHP, Objek Wisata

\begin{abstract}
Tourist attraction is the embodiment of human creation, lifestyle, art of culture and history of the nation and place of nature that has the attraction to visit. Potential tourist attraction in the city of Lubuklinggau is currently not managed optimally, so the existence of the attraction has not received a positive response from tourists who visit. This can be seen from the decreasing number of tourists who visit each year. One factor of the declining number of tourists visiting is the inadequate tourist attraction resources. To be able to increase the number of tourists visiting the course required a decision support system to improve the quality of tourist attractions. Where the criteria used based on the results of interviews at the Department of Culture and Tourism of attraction, accessibility, accommodation and supporting facilities. This decision support system applies Analytical Hierarchy Process method with expert choice test software. This research has a purpose in order to reduce the assessment subjectively to the improvement of the quality of the object, resulting in a precise and objective assessment system of the tourist attraction to be developed.
\end{abstract}

Keywords — Decision Support System, AHP, Tourist Attraction 


\section{PENDAHULUAN}

Kota Lubuklinggau merupakan salah satu kota di Sumatera Selatan yang memiliki daya tarik dari sektor pariwisata. Dimana kota ini memiliki banyak objek wisata yang dijadikan sebagai salah satu sumber pendapatan asli daerah diantaranya air terjun temam, bukit sulap, bendungan water vang, dan kampung warna warni. Selain itu peningkatan kualitas obyek wisata merupakan peran serta pemerintah daerah dalam mengenalkan keanekaragaman wisata yang ada di Indonesia [1]. Peningkatan kualitas objek wisata Kota Lubuklinggau saat ini dilakukan dengan cara penambahan dan perbaikan sarana pendukung yang ada di setiap objek wisata dengan memperhatikan banyaknya jumlah pengunjung objek wisata [2]. Kegiatan tersebut dilakukan bertujuan agar minat masyarakat mengunjungi objek wisata terus meningkat baik wisatawan lokal maupun mancanegara. Pengembangan objek wisata secara menyeluruh mengakibatkan kebutuhan alokasi dana yang cukup besar, sehigga perlu dilakukan penilaian skala prioritas untuk peningkatan kualitas objek wisata. Informasi data dari Dinas Kebudayaan dan Pariwisata Kota Lubuklinggau jumlah wisatawan yang berkunjung di seluruh objek wisata mengalami penuruhan yaitu pada tahun 2014 berjumlah 150.306, tahun 2015 berjumlah 150.134 dan pada tahun 2016 berjumlah 146.870. Untuk meningkatkan jumlah pengunjung tentunya perlu mempertimbangkan metode dalam menentukan kriteria yang mempengaruhi peningkatan jumlah pengunjung di setiap objek wisata yang ada di Kota Lubuklinggau. Agar upaya dalam peningkatan kualitas objek wisata sesuai dengan tujuan yang ingin dicapai, maka dibutuhkan sistem pendukung keputusan yang mampu membantu pihak pengambil kebijakan dalam menentukan obyek wisata secara prioritas yang perlu ditingkatkan.

Menyadari pentingnya dalam menentukan peningkatan kualitas objek wisata berdasarkan skala prioritas, oleh karna itu dibutuhkan suatu sistem yang dapat membantu dalam pengambilan keputusan pengembangan objek wisata di pemerintah Kota Lubuklinggau. Dengan adanya sistem pendukung keputusan, pemerintah daerah dapat dengan cepat dan tepat dalam melakukan pengembangan objek wisata. Sistem penunjang keputusan merupakan pendekatan sistematis, yang diawali dengan permasalahan pembuatan keputusan manajemen, pengumpulan fakta-fakta, menetapkan sejumlah kriteria keputusan untuk memilih alternatif-alternatif tindakan yang paling tepat sebagai solusi keputusan [3]. Adapun metode yang akan digunakan dalam penelitian ini adalaha Metode Analytic Hierarchy Process (AHP) yang merupakan alat pengambilan keputusan dari beberapa kriteria yang merupakan nilai pendekatan eigen untuk perbandingan berpasangan dan menyediakan metodologi untuk mengkalibrasi numerik untuk skala pengukuran kuantitatif serta sebagai pertunjukan kualitatif [4].

Berdasarkan pengamatan penelitian terdahulu sebagai bahan komparasi yaitu penelitian yang dilakukan Linda Marlinda. Pada jurnal tersebut, Sistem pendukung keputusan pemilihan tempat wisata yogyakarta menggunakan metode ELECTRE dengan menggunakan beberapa kriteria penilaian yaitu biaya, jarak, waktu, keindahan alam dan keamanan [5].

Jurnal kedua yang dijadikan acuan yaitu penelitian Marlina, Iqbal. Dalam jurnal tersebut, penelitian yang dilakukan mengenai implementasi sistem pendukung keputusan pengembangan lokasi objek wisata di kabupaten bireuen. Adapun kriteria yang digunakan yaitu jarak, akses, kesediaan air bersih, keamanan dan fasilitas [6].

Jurnal ketiga yang dijadikan acuan yaitu penelitian A Yani Ranius. Dalam proceeding tersebut, penelitian yang dilakukan tentang sistem pendukung keputusan penentuan destinasi wisata unggulan di kota palembang. Adapun kriteria yang digunakan yaitu ketersediaan sumberdaya, daya tarik, fasilitas, akses, kesiapan dan keterlibatan masyarakat, posisi strategis, dan potensi pasar [7].

Refrensi keempat yang dijadikan acuan yaitu penelitian yang dilakukan oleh Dani Eko P S. Pada skripsi tersebut, Sistem Pendukung Keputusan pemilihan objek wisata di surakarta menggunakan metode fuzzy tahani. Adapun kriteria yang dipakai yaitu harga, fasilitas, dan lama berdiri objek wisata [8].

Sedangkan jurnal kelima yang dijadikan acuan adalah penelitian I Wayan Aditya., Dkk. Pada jurnal tersebut, membahas tentang Pengembangan Sistem pendukung keputusan berbasis 
android untuk penentuan daerah tujuan wisata di bali dengan menggunakan metode fuzzy tahani. Adapun kriteria yang dipilih adalah jarak, biaya dan waktu [9].

Berdasarkan hasil analisa dan pengamatan dari beberapa sumber refrensi diatas, tentunya ada beberapa perbedaan pada penelitian yang akan dilakukan. Perbedaan pada penelitian ini adalah dari metode dan kriteria yang digunakan pada jurnal $[5,8,9]$ yaitu menggunakan fuzzy tahani dan ELECTRE. Sedangkan pada penelitian lainnya[6,7] terdapat kesamaan pada metode, Sedangkan kriteria yang digunakan pada penelitian ini yaitu daya tarik, aksesibilitas, akomodasi dan sarana pendukung. kriteria tersebut diperoleh berdasarkan sumber refrensi dan hasil wawancara terstruktur melalui beberapa pertanyaan yang telah disediakan berkenaan dengan pelaksanaan peningkatan kualitas objek wisata di Kota Lubuklinggau kepada pihak responden yaitu pegawai di Dinas Kebudayaan dan Pariwisata Kota Lubuklinggau.

\section{METODE PENELITIAN}

Metode yang digunakan pada penelitian ini adalah metode AHP karena metode ini menerapkan proses penilaian berdasarkan beberapa kriteria yang dibandingkan berpasangan untuk menghasilkan alternatif terbaik. Tahapan kegiatan menggunakan metode Analytical Hierarchy Process dalam upaya peningkatan kualitas objek wisata di Kota Lubuklinggau ditunjukkan pada Gambar 1.

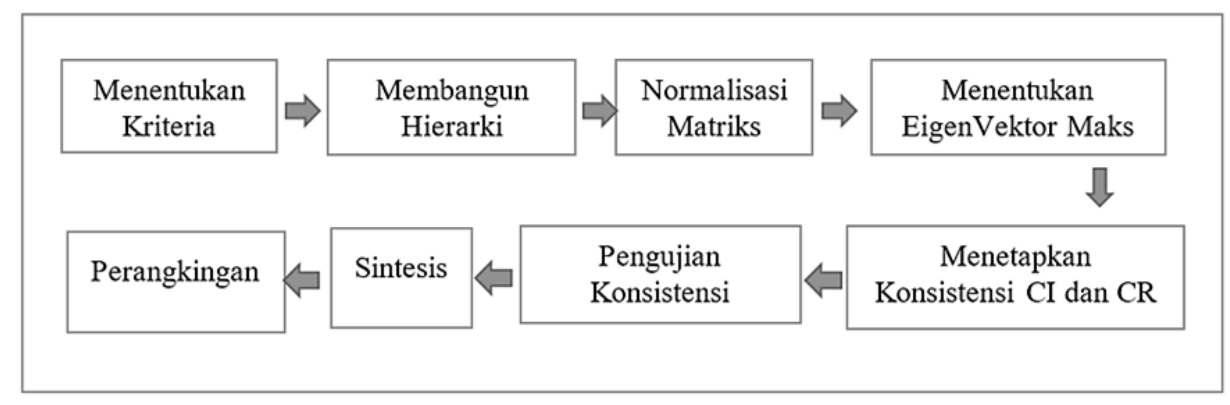

Gambar 1. Tahapan kegiatan menggunakan metode AHP untuk peningkatan kualitas objek wisata

Dalam menghadapi banyaknya persoalan maka dibutuhkan skala terbaik untuk dapat mengekspresikan pendapat. Nilai dan definisi pendapat kualitatif dari skala perbandingan bisa diukur menggunakan Tabel 1 [10].

Tabel 1. Skala Penilaian Perbandingan Pasangan

\begin{tabular}{|l|l|}
\hline $\begin{array}{l}\text { Intensitas } \\
\text { Kepentingan }\end{array}$ & Keterangan \\
\hline 1 & Kedua elemen sama penting \\
\hline 3 & Elemen yang satu sedikit lebih penting daripada elemen yang lainnya \\
\hline 5 & Elemen yang satu lebih penting dari pada elemen lainnya \\
\hline 7 & Satu elemen jelas lebih mutlak penting dari pada elemen lainnya \\
\hline 9 & Satu elemen mutlak penting dari pada elemen lainnya \\
\hline $2,4,6,8$ & Nilai - nilai antara dua nilai pertimbangan yang berdekatan \\
\hline Kebalikan & $\begin{array}{l}\text { Jika aktivitas i mendapat satu angka dibandingkan dengan aktivitas } \mathrm{j}, \\
\text { maka i memiliki nilai kebalikannya dibandingkan dengan i }\end{array}$ \\
\hline
\end{tabular}

Setelah tahapan perbandingan kriteria dan alternatif maka langkah selanjutnya menentukan synthesis of Priority, yaitu dilakukan perbandingan berpasangan pada kriteria dan alternatif. Bobot dan prioritas dihitung dengan perubahan dalam bentuk matriks. Hasil 
perhitungan akan menghasilkan Logical Consistency. Untuk mengetahui seberapa baik konsistensi yang ada dapat menggunakan rumus hitung Consistency Index (CI) dengan rumus CI $=(\lambda$ maks-n) $/ \mathrm{n}$. Dimana n=banyaknya elemen. Kemudian menghitung Consistency Ratio (CR) dengan rumus: $C R=C I / R C$. Sedangkan RC adalah Random Cosistency dengan skala penilaian 1 sampai 9 beserta kebalikannya dapat dilihat pada tabel 2. Jika nilainya lebih dari 10\%, maka penilaian data judgment harus diperbaiki. Namun jika rasio konsistensi (CI/CR) kurang atau sama dengan 0,1, maka hasil perhitungan bisa dinyatakan benar [11].

Tabel 2. Daftar Indeks Random Konsistensi

\begin{tabular}{|l|l|}
\hline Ukuran Matriks & Nilai IR \\
\hline 1 dan 2 & 0,00 \\
\hline 3 & 0,58 \\
\hline 4 & 0,90 \\
\hline 5 & 1,12 \\
\hline 6 & 1,24 \\
\hline 7 & 1,32 \\
\hline 8 & 1,41 \\
\hline 9 & 1,45 \\
\hline 10 & 1,49 \\
\hline
\end{tabular}

\section{HASIL DAN PEMBAHASAN}

Dari hasil observasi dan wawancara yang dilakukan diperoleh data objek wisata alam yang ada di Kota Lubuklinggau sebanyak 10 objek wisata. Objek wisata yang dikelola dan rutin dikunjungi oleh wisatawan sebanyak 4 objek wisata yang tersebar di beberapa kecamatan, yaitu Kecamatan Lubuklinggau Selatan, Kecamatan Lubuklinggau Utara, Lubuklinggau Timur dan Lubuklinggau Barat. Adapun objek wisata dapat dilihat pada Tabel 3.

Tabel 3. Daftar Objek Wisata

\begin{tabular}{|l|l|l|}
\hline No & Objek Wisata & Lokasi \\
\hline 1 & Air Terjun Temam & Kecamatan Lubuklinggau Selatan \\
\hline 2 & Bukit Sulap & Kecamatan Lubuklinggau Utara \\
\hline 3 & Bendungan Water Vang & Kecamatan Lubuklinggau Timur \\
\hline 4 & Kampung Warna Warni & Kecamatan Lubuklinggau Barat \\
\hline
\end{tabular}

\subsection{Menentukan Kriteria}

Dalam penelitian ini, peneliti menggunakan kriteria berdasarkan sumber refrensi dan hasil wawancara yang merujuk pada data hasil sebaran kuisioner yang dilakukan oleh pihak Dinas Kebudayaan dan Pariwisata kepada pengunjung di tahun 2014. Peneliti hanya menggunakan sample 10 responden penilaian objek wisata di Kota Lubuklinggau yang perlu dilakukan uji validitas terhadap kuisioner dengan rumus persamaan ke-1 sebagai berikut :

$$
r_{x y}=\frac{\mathrm{N} \sum X Y-\left(\sum X\right)\left(\sum Y\right)}{\sqrt{\left\{N \sum X^{2-\left(\sum Y\right)} 2-\left(\sum Y\right)^{2}\right\}\left\{N \sum Y^{2}-\sum X^{2}\right.}}
$$

Keterangan :

$\mathrm{X}=$ Hasil kuisioner pertanyaan ke-i

$\mathrm{Y}=$ jumlah keseluruhan dari kuisioner 
Citec Journal, Vol. 4, No. 3, Mei 2017 - Juli 2017

ISSN: 2460-4259

Uji validitas dilakukan pada setiap poin kriteria. Hasilnya jika dibandingkan dengan $r$ tabel dengan $\mathrm{df}=\mathrm{N}-\mathrm{K}$ dan dengan nilai alfa $=5 \%$, maka Jika $\mathrm{r}$ hitung $<\mathrm{r}$ tabel $=$ tidak 2 . Jika $\mathrm{r}$ hitung $>$ $\mathrm{r}$ tabel = valid. Perhitunga Rt [12] bisa dilihat pada persamaan ke-2.

$$
r=\frac{t}{\sqrt{d f+t^{2}}}
$$

Keterangan :

$\mathrm{r}=$ nilai $\mathrm{r}$ tabel

$\mathrm{t}=$ nilai $\mathrm{t}$ tabel

$\mathrm{df}=$ degree of freedom

Dalam penelitian ini uji validitas terhadap kuisioner menghasilkan nilai signifikasi dengan membandingkan nilai $r$ hitung dengan $r$ tabel untuk degree of freedom dengan alpha $5 \%$ maka didapatkan $\mathrm{r}$ tabel=0,632.

Tabel 4. Perhitungan Uji Validitas Kuisioner penilaian Objek Wisata

\begin{tabular}{|c|c|c|c|c|c|c|c|c|c|c|}
\hline R/K & K1 & K2 & K3 & K4 & K5 & K6 & K7 & K8 & K9 & K10 \\
\hline 1 & 5 & 3 & 4 & 4 & 3 & 4 & 4 & 4 & 4 & 4 \\
\hline 2 & 5 & 1 & 4 & 4 & 4 & 5 & 4 & 4 & 4 & 4 \\
\hline 3 & 4 & 2 & 4 & 3 & 4 & 4 & 4 & 4 & 5 & 5 \\
\hline 4 & 5 & 3 & 4 & 4 & 3 & 5 & 4 & 3 & 4 & 4 \\
\hline 5 & 4 & 4 & 2 & 4 & 3 & 5 & 5 & 5 & 5 & 5 \\
\hline 6 & 5 & 2 & 4 & 5 & 4 & 5 & 4 & 3 & 5 & 4 \\
\hline 7 & 5 & 3 & 2 & 5 & 3 & 4 & 4 & 1 & 4 & 1 \\
\hline 8 & 5 & 2 & 4 & 4 & 4 & 5 & 5 & 5 & 5 & 4 \\
\hline 9 & 5 & 1 & 5 & 5 & 4 & 5 & 5 & 5 & 5 & 4 \\
\hline 10 & 4 & 1 & 4 & 4 & 3 & 5 & 4 & 4 & 4 & 4 \\
\hline Rh & 0,034 & $-0,158$ & 0,498 & $-0,052$ & 0,526 & 0,574 & $\mathbf{0 , 7 0 9}$ & $\mathbf{0 , 8 4 9}$ & $\mathbf{0 , 7 1 1}$ & $\mathbf{0 , 7 2 6}$ \\
\hline Rt & 0,632 & 0,632 & 0,632 & 0,632 & 0,632 & 0,632 & $\mathbf{0 , 6 3 2}$ & $\mathbf{0 , 6 3 2}$ & $\mathbf{0 , 6 3 2}$ & $\mathbf{0 , 6 3 2}$ \\
\hline & Tidak & Tidak & Tidak & Tidak & Tidak & Tidak & Valid & Valid & Valid & Valid \\
\hline
\end{tabular}

Keterangan :

$\mathrm{K} 1$ = Ketersediaan SDM, K2 = keterlibatan masyarakat, K3 = posisi strategis, K4 = potensi pasar, K5 = Keamanan, K6 = Kebersihan, K7 = Daya Tarik, K8 = Aksesibilitas, K9 = Akomodasi, K10 $=$ Saran Pendukung

Dilihat dari hasil perhitungan pada Tabel 4 dapat disimpulkan kriteria yang dinyatakan valid berdasarkan uji validasi kuisioner penilaian dari responden adalah daya tarik, aksesibilitas, akomodasi dan sarana pendukung sehingga dapat digunakan sebagai sampel penelitian ini.

\subsection{Membangun Hierarki}

Dari kriteria dan alternatif yang diperoleh selanjutnya dilakukan tahapan AHP dengan membangun hierarki seperti pada Gambar 2 yaitu dengan menentukan tujuan yang merupakan sasaran sistem secara keseluruhan di tingkat teratas. 


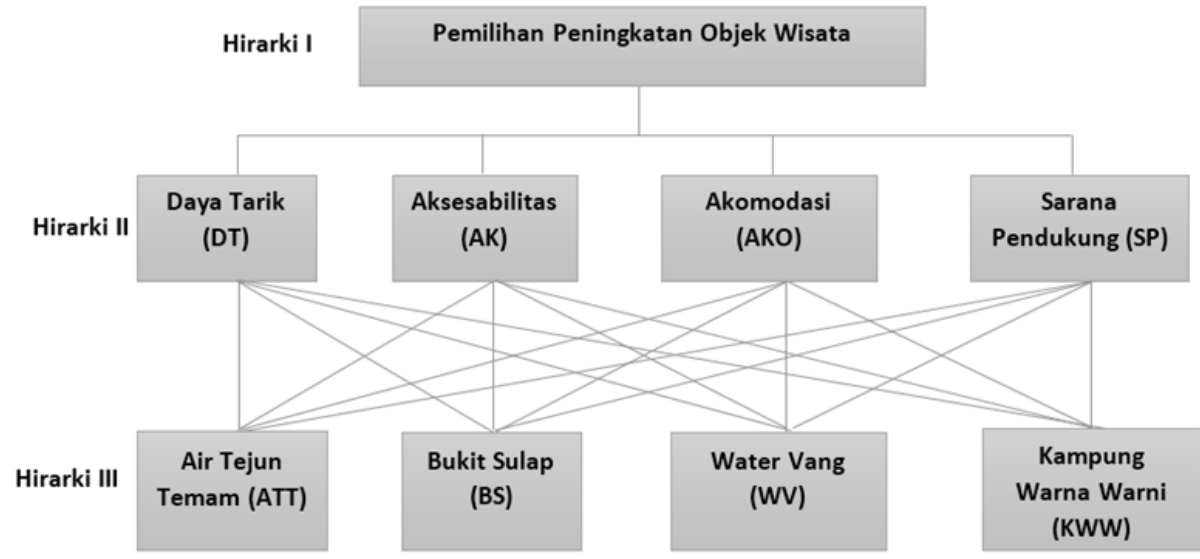

Gambar 2. Hierarki Peningkatan Kualitas Objek Wisata

\subsection{Menentukan Matriks perbandinfan Berpasangan}

Berdasarkan model dan tahapan AHP yang telah terbentuk, tahap selanjutnya adalah menyusun matriks perbandingan berpasangan pada setiap kriteria dan setiap alternatif. Penentuan nilai-nilai pada matriks perbandingan berpasangan dilakukan oleh Bagian Kepariwisataan. Nilai yang diperoleh pada kolom DT dan AK didapat dari hasil perhitungan 1.000/ nilai pada kolom AK. Begitu juga dengan nilai-nilai yang lain diperoleh dengan perhitungan yang sama. Hasil perhitungan dapat dilihat pada Tabel 5.

Tabel 5. Matriks Kriteria Perbandingan Berpasangan

\begin{tabular}{|l|l|l|l|l|}
\hline Kriteria & DT & AK & AKO & SP \\
\hline DT & 1.000 & 0.200 & 0.200 & 5.000 \\
\hline AK & 5.000 & 1.000 & 1.000 & 9.000 \\
\hline AKO & 5.000 & 1.000 & 1.000 & 9.000 \\
\hline SP & 0.200 & 0.111 & 0.111 & 1.000 \\
\hline Jumlah & $\mathbf{1 1 . 2 0 0}$ & $\mathbf{2 . 3 1 1}$ & $\mathbf{2 . 3 1 1}$ & $\mathbf{2 4 . 0 0 0}$ \\
\hline
\end{tabular}

\subsection{Normalisasi}

\subsection{1. $\quad$ Matriks Kriteria}

Pada tahapan ini dilakukan perhitungan untuk mengetahui nilai normalisasi matriks kriteria yaitu nilai kolom lama atau DT dibagi dengan kolom jumlah DT. Proses ini dilakukan sampai dengan kolom SP. Kemudian dilakukan perhitungan nilai prioritas atau dikenal dengan eigenvektor yang dihasilkan dari kolom jumlah dibagi dengan jumlah kriteria, pada penelitian ini ada 4 kriteria. Hasil perhitungan nilai prioritas atau eigenvektor dapat dilihat pada Tabel 6.

Tabel 6. Normalisasi Matriks Kriteria

\begin{tabular}{|c|c|c|c|c|c|c|}
\hline Kriteria & DT & AK & AKO & SP & Jumlah & EigenVektor \\
\hline DT & 0.089 & 0.087 & 0.087 & 0.208 & $\mathbf{0 . 4 7 1}$ & $\mathbf{0 . 1 1 7}$ \\
\hline AK & 0.446 & 0.433 & 0.433 & 0.357 & $\mathbf{1 . 6 8 7}$ & $\mathbf{0 . 4 2 2}$ \\
\hline AKO & 0.446 & 0.433 & 0.433 & 0.357 & $\mathbf{1 . 6 8 7}$ & $\mathbf{0 . 4 2 2}$ \\
\hline SP & 0.018 & 0.048 & 0.048 & 0.042 & $\mathbf{0 . 1 5 6}$ & $\mathbf{0 . 0 3 9}$ \\
\hline
\end{tabular}


Citec Journal, Vol. 4, No. 3, Mei 2017 - Juli 2017

\subsubsection{Matriks Alternatir Kriteria}

Pada matriks alternatif kriteria dilakukan perhitungan untuk mengetahui nilai prioritas atau eigenvektor alternatif terhadap kriteria yaitu dengan persamaan yang sama pada normalisasi matriks kriteria. Hasil normalisasi matriks alternatif kriteria dapat dilihat pada Tabel 7.

Tabel 7. Normalisasi Matriks Alternatif Kriteria

\begin{tabular}{|c|c|c|c|c|}
\hline \multirow{2}{*}{$\begin{array}{c}\text { Kriteria / } \\
\text { Alternatif }\end{array}$} & \multicolumn{4}{|c|}{ Eigenvektor (EV) } \\
\cline { 2 - 5 } & DT & AK & AKO & SP \\
\hline ATT & 0.051 & 0.051 & 0.291 & 0.274 \\
\hline BS & 0.441 & 0.187 & 0.590 & 0.581 \\
\hline WV & 0.206 & 0.354 & 0.062 & 0.077 \\
\hline KWW & 0.302 & 0.408 & 0.057 & 0.068 \\
\hline Total & $\mathbf{1 . 0 0 0}$ & $\mathbf{1 . 0 0 0}$ & $\mathbf{1 . 0 0 0}$ & $\mathbf{1 . 0 0 0}$ \\
\hline
\end{tabular}

\subsection{Menetukan Nilai Eigen Vektor Maksimal}

Menentukan nilai eigenvektor maksimal ( $\lambda$ Maks) kriteria dan alternatif terhadap kriteria yang digunakan untuk mengetahui nilai concistency index dengan rumus persamaan ke-3:

$$
\begin{aligned}
& \lambda \text { Maks }=\text { eigenvektor } x \text { jumlahkolom } \\
& \lambda \text { Maks }=0.117 * 11.200=\mathbf{1 . 3 1 0}
\end{aligned}
$$

Perhitungan ini dilakukan sampai dengan nilai prioritas dan nilai matriks kriteria SP Maka diperoleh eigenvektor maksimal seperti pada Tabel 8.

Tabel 8. EigenVektor Maksimal Kriteria

\begin{tabular}{|l|c|}
\hline Kriteria & $\mathrm{EV} *$ Total Matriks \\
\hline Daya Tarik & 1.310 \\
\hline Aksesibilitas & 0.975 \\
\hline Akomodasi & 0.975 \\
\hline Sarana Pendukung & 0.936 \\
\hline $\boldsymbol{\lambda}$ Maks & $\mathbf{4 . 1 9 6}$ \\
\hline
\end{tabular}

Untuk eigenvektor maksimal alternatif terhadap kriteria dilakukan dengan persamaan yang sama pada eigenvektor maksimal kriteria sehingga diperoleh nilai eigenvektor masimal alternatif terhadap kriteria seperti pada Tabel 9.

Tabel 9. EigenVektor Maksimal Alternatif Kriteria

\begin{tabular}{|l|l|c|c|c|}
\hline Alternatif & DT & AK & AKO & SP \\
\hline Air Terjun Temam & 0.969 & 0.969 & 1.260 & 1.219 \\
\hline Bukit Sulap & 0.945 & 0.945 & 0.926 & 0.944 \\
\hline Water Vang & 1.071 & 1.071 & 0.930 & 0.924 \\
\hline Kampung Warna Warni & 1.110 & 1.110 & 1.026 & 1.020 \\
\hline $\boldsymbol{\lambda}$ Maks & $\mathbf{4 . 0 9 5}$ & $\mathbf{4 . 0 9 5}$ & $\mathbf{4 . 1 4 2}$ & $\mathbf{4 . 1 0 7}$ \\
\hline
\end{tabular}




\subsection{Menghitung Nilai Consistency Index}

Dari nilai eigenvektor maksimal yang diperoleh, maka langkah selanjutnya menentukan nilai indeks konsistensi atau Consistency Index (CI) maka rumus persamaan ke-4 yang digunakan sebagai berikut:

$$
\begin{aligned}
& C I=\frac{(\lambda M a k s-\mathrm{n})}{\mathrm{n}-1} \\
& C I=\frac{(4.196-4)}{4-1} \\
& C I=\frac{0.196}{3}=0.0653
\end{aligned}
$$

hingga diperoleh nilai $C I$ seperti pada Tabel 10 sebagai berikut:

Tabel 10. Consistency Index

\begin{tabular}{|c|c|}
\hline Matriks & CI \\
\hline I & 0.0653 \\
\hline II & 0.0317 \\
\hline III & 0.0273 \\
\hline IV & 0.0473 \\
\hline V & 0.0357 \\
\hline
\end{tabular}

Nilai CI yang diperoleh pada Tabel 8 selanjutnya dibandingkan dengan nilai random index (RI) untuk ukuran matriks = 4 (karena terdapat 4 elemen dalam tiap matriks), maka nilai random consistency yang digunakan adalah 0,9 . Konsistensi yang dapat diterima apabila nilai $C R<10 \%(C R<0,1)$.

\subsection{Menghitung Nilai Consistency Ratio}

Untuk dapat mengetahui nilai Consistency Ratio (CR) dapat dihitung rumus persamaan ke-5 sebagai berikut :

$$
\begin{aligned}
& C R=\frac{\mathrm{CI}}{\mathrm{IR}} \\
& C I=\frac{0.0653}{0.900}=0.07256
\end{aligned}
$$

Dari hasil perhitungan dengan persamaan diatas menunjukkan bahwa nilai CR $<0.1$, maka konsistensi dari hasil pembobotan dapat diterima berdasarkan konsistensi pengisiannya seperti hasil pada Tabel 11.

Tabel 11. Consistency Rasio

\begin{tabular}{|c|c|c|c|}
\hline Matriks & CI & IR & CR \\
\hline I & 0.0653 & \multirow{2}{*}{$\mathbf{C I} / \mathbf{0 . 9}$} & 0.07256 \\
\hline II & 0.0317 & & 0.03522 \\
\hline III & 0.0273 & & 0.03033 \\
\hline IV & 0.0473 & & 0.05256 \\
\hline V & 0.0357 & & 0.03967 \\
\hline
\end{tabular}


Citec Journal, Vol. 4, No. 3, Mei 2017 - Juli 2017

ISSN: 2460-4259

\subsection{Melakukan Proses Sintetis}

Proses sintesis atau iterasi matriks. Untuk menentukan bobot prioritas pada kriteria dan alternatif kriteria dengan perkalian (baris x kolom) dan proses iterasi dilakukan minimal 3 kali. Maka hasil iterasi dapat dilihat pada Tabel 12 dan Tabel 13 sebagai berikut:

Tabel 12. Bobot Prioritas Kriteria

\begin{tabular}{|c|c|c|}
\hline Iterasi ke-2 $(\mathrm{X})$ & Iterasi Ke-3 $(\mathrm{Y})$ & Selisih $(\mathrm{X}-\mathrm{Y})$ \\
\hline 0.114 & 0.114 & 0.000 \\
\hline 0.424 & 0.424 & 0.000 \\
\hline 0.424 & 0.424 & 0.000 \\
\hline 0.037 & 0.037 & 0.000 \\
\hline
\end{tabular}

Pada proses sintesis, memperoleh nilai selisih hasil normalisasi yang bernilai 0 , artinya proses iterasi tidak perlu lagi dilanjutkan. Tiap-tiap elemen penyusun kriteria dapat disusun yaitu $\mathrm{DT}=0,114, \mathrm{AK}=0,424$, AKO $=0,424$, dan SP $=0,037$. Dari hasil sintesis aspek utama yang mempengaruhi pemilihan peningkatan kualitas objek wisata adalah kriteria Aksesibilitas dan Akomodasi.

Tabel 13. Bobot Prioritas Alternatif

\begin{tabular}{|l|l|l|l|l|}
\hline \multicolumn{1}{|c|}{ Objek wisata } & Bobot DT & Bobot AK & Bobot AKO & Bobot SP \\
\hline Air Terjun Temam (ATT) & 0.050 & 0.050 & 0.287 & 0.271 \\
\hline Bukit Sulap (BS) & 0.444 & 0.185 & 0.597 & 0.587 \\
\hline Water Vang (WV) & 0.203 & 0.353 & 0.061 & 0.076 \\
\hline Kampung Warna Warni (KWW) & 0.303 & 0.411 & 0.055 & 0.066 \\
\hline
\end{tabular}

\subsection{Perbangkitan}

Pada proses perhitungan melalui proses sintesis diperoleh bobot prioritas kriteria dan bobot prioritas alternatif terhadap kriteria sehingga dapat dilakukan proses perangkingan dengan menggunakan rumus persamaan ke-6 sebagai berikut :

$$
\text { Hasil }=\sum \text { (prioritas kriteria } \mathrm{x} \text { prioritas alternatif) }
$$

Maka diperoleh perhitungan hasil akhir seperti pada Tabel 14.

Tabel 14. Perhitungan Hasil Akhir

\begin{tabular}{|l|c|c|c|c|c|}
\hline \multicolumn{1}{|c|}{ Objek Wisata } & DT & AK & AKO & SP & Hasil \\
\hline Air Terjun Temam (ATT) & 0.0057 & 0.0212 & 0.1217 & 0.0100 & 0.159 \\
\hline Bukit Sulap (BS) & 0.0506 & 0.0784 & 0.2531 & 0.0217 & 0.404 \\
\hline Water Vang (WV) & 0.0231 & 0.1497 & 0.0259 & 0.0028 & 0.202 \\
\hline Kampung Warna Warni (KWW) & 0.0345 & 0.1743 & 0.023 & 0.0024 & 0.235 \\
\hline
\end{tabular}

Sehingga dari hasil perhitungan pada tabel 14 diatas, diperoleh rating untuk objek wisata yang akan dikembangkan untuk peningkatan kualitas baik dari nilai tertinggi sampai nilai terendah. seperti terlihat pada Tabel 15. 
Tabel 15. Rating Keputusan

\begin{tabular}{|l|c|c|l|l|l|}
\hline \multicolumn{1}{|c|}{ Objek Wisata } & \multicolumn{1}{c|}{ DT } & \multicolumn{1}{c|}{ AK } & \multicolumn{1}{c|}{ AKO } & \multicolumn{1}{c|}{ SP } & \multicolumn{1}{c|}{ Hasil } \\
\hline Bukit Sulap (BS) & 0.0506 & 0.0784 & 0.2531 & 0.0217 & 0.404 \\
\hline Kampung Warna Warni (KWW) & 0.0345 & 0.1743 & 0.023 & 0.0024 & 0.235 \\
\hline Water Vang (WV) & 0.0231 & 0.1497 & 0.0259 & 0.0028 & 0.202 \\
\hline Air Terjun Temam (ATT) & 0.0057 & 0.0212 & 0.1217 & 0.0100 & 0.159 \\
\hline
\end{tabular}

\subsection{Pengujian Hasil menggunakan Expert Choice}

Pada tahap pengujian ini dilakukan komparasi hasil perhitungan manual dengan perhitungan menggunakan software pengujian expert choice dimana diperoleh hasil objek wisata yang memiliki nilai terbesar adalah objek wisata bukit sulap. dimana hasil analisis yang dilakukan dengan metode AHP menunjukan prioritas objek wisata yang sama, namun terdapat selisih dari hasil sintesis dikarenakan analisis menggunakan expert choice dipengaruhi oleh tingkat inkonsistensi sebesar 0,04 seperti pada Gambar 3 sebagai berikut.

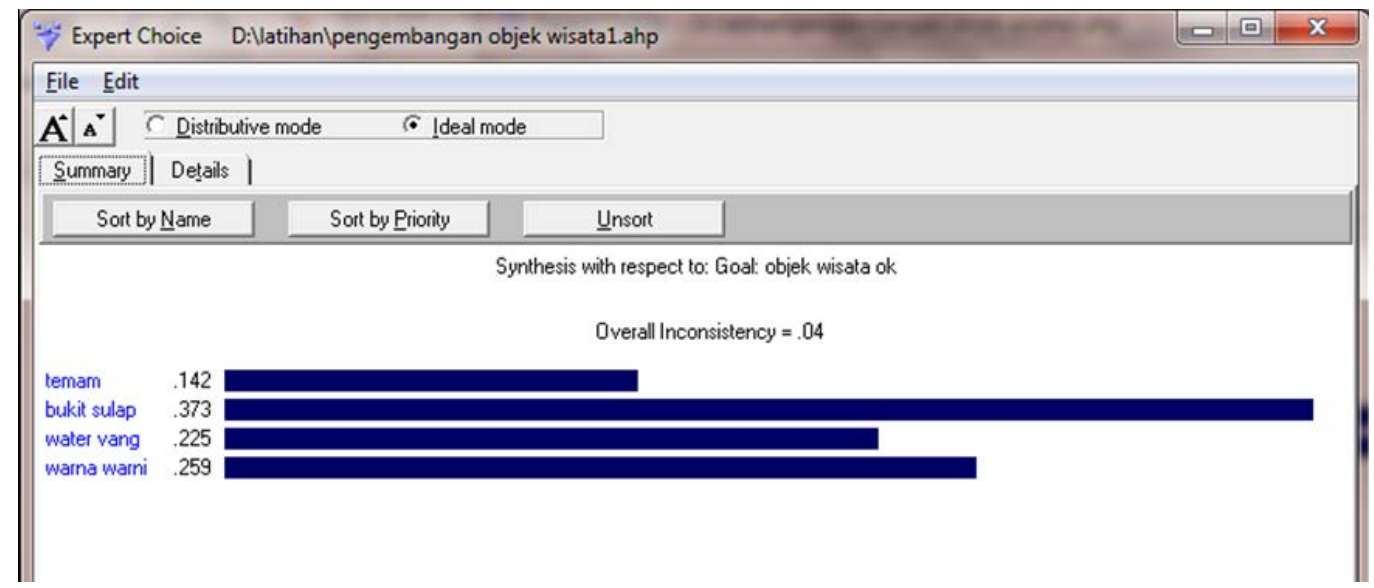

Gambar 3. Hasil Perhitungan Prioritas Pengembangan Objek Wisata menggunakan Expert Choice

\section{KESIMPULAN}

Dari hasil analisa sistem pendukung keputusan pada penelitian ini maka dapat disimpulkan bahwa:

1. Sistem pendukung keputusan menggunakan metode AHP menghasilkan informasi tentang objek wisata yang layak untuk dikembangkan untuk peningkatan kualitas objek wisata di Kota Lubuklinggau.

2. Pihak pengambil keputusan dapat menggunakan hasil keluaran dari sistem pendukung keputusan sebagai bahan pertimbangan dalam pengembangan objek wisata, sehingga peningkatan kualitas objek wisata dapat dilakukan dengan cepat dan tepat.

3. Software pengujian expert choice dapat memenuhi kebutuhan untuk membantu dalam upaya peningkatan kualitas objek wisata yang sesuai dengan kriteria-kriteria yang telah ditentukan.

\section{SARAN}

Disarankan untuk penelitian berikutnya perlu dikembangan dengan melakukan komparasi metode Analytical Hierarchy Process dengan metode Analytic Network Process agar hasil yang ingin dicapai lebih akurat. 


\section{DAFTAR PUSTAKA}

[1] Republik Indonesia, 2009, Undang-undang Republik Indonesia No.10 tahun 2009 tentang Kepariwisataan, Jakarta

[2] Lubuklinggau, 2012, Perda Kota Lubuklinggau No 1 Tahun 2012 tentang Rencana Tata Ruang Wilayah Kota Lubuklinggau 2012-2032, Lubuklinggau.

[3] Turban, E., 2005, Decision Support Systems and Intelligent Systems; 7th edition. Andi Offset, Yogyakarta.

[4] Vaidya, O. S., Kumar, S., 2006, Analytic hierarchy process: An overview of applications, European Journal of Operational Research, Vol 169, No. 1, hal. 1-29.

[5] Linda, M., 2016, Sistem pendukung keputusan pemilihan tempat wisata yogyakarta menggunakan metode ELECTRE, Seminar Nasional Sains dan Teknologi, Jakarta, 8 November 2016.

[6] Marlina., Ikbal., 2016, Implementasi Sistem Pendukung Keputusan Pengembangan Objek Wisata di Kabupaten Bireuen, Jurnal TIKA, Vil. 1, No. 2, hal 48-63.

[7] Ranius, A.Y., 2015, Sistem Pendukung Keputusan Penentuan Destinasi Wisata Unggulan di Kota Palembang, Proceeding SNIT Peluang dan Tantangan Indonesia Dalam Menyikapi AFTA 2015, Palembang, 23 Mei 2015.

[8] Phurnomo, D. E. S., 2013, Sistem Pendukung Keputusan Pemilihan Objek Wisata di Surakarta menggunakan metode Fuzzy Tahani, Skripsi, Program Studi Teknik Informatika, Universitas STIKUBANK Semarang.

[9] Sudyatmika, I. W. A., Darmawiguna, I. G. M., Wirawan, I. M. A., Pengembangan Sistem Pendukung Keputusan Berbasis Android untuk Penentuan Daerah Tujuan Wisata di Bali dengan menggunakan Metode Fuzzy Tahani, Jurnal KARAMPATI, Vol. 4 No. 4, hal 1-10.

[10] Kusrini, 2007, Konsep dan Aplikasi Sistem Pendukung Keputusan, Andi, Yogyakarta.

[11] Saaty, T. L., 2008, Decision Making with the Analytic Hierarchy Process. Int. J. Services Sciences, No. 1, Vol. 1, Hal $83-98$.

[12] Norhikmah., Kusrini., Arief, M.R., 2014, Perancangan Sistem Pendukung Keputusan dalam Memilih Sekolah Tinggi Ilmu Kesehatan di Yogyakarta, Citec Journal, Vol. 1, No. 2. 